\title{
Linking tree growth rate, damage repair, and susceptibility to a genus-specific pest infestation
}

\author{
Kayla N. Boyes ${ }^{1} \cdot$ Kathryn G. Hietala-Henschell $^{2} \cdot$ Alexander P. Barton $^{1}$ • \\ Andrew J. Storer ${ }^{2} \cdot$ Jordan M. Marshall $^{1}$
}

Received: 10 October 2018/Accepted: 9 December 2018/Published online: 6 March 2019

(C) The Author(s) 2019

\begin{abstract}
Pest preference and subsequent susceptibility of a host individual is likely related to previous growth patterns in that host. Emerald ash borer (Agrilus planipennis Fairmaire) is a pestiferous beetle introduced to North America from Asia. While all species of ash are susceptible to attack, some individual trees appear to survive infestation. We selected ash trees in southeastern Michigan, collected cores and categorized trees as high tolerance to emerald ash borer attack (high overall health, low crown dieback), low tolerance (low overall health, high crown dieback) and intermediate tolerance (in-between the other categories). We artificially wounded trees and measured wound closure after 3 years. Ring width indices were not correlated between high and low tolerance trees. Regression slopes comparing growth and years were significantly different between the three tolerance categories, with high tolerance trees having the steepest slope. Wound closure was greatest in high tolerance trees. High tolerance trees demonstrating more rapid
\end{abstract}

Project funding: This work was supported in part by the Purdue University Fort Wayne Honors Program and the John Z. Duling Grant Program from the Tree Research and Education Fund.

The online version is available at http://www.springerlink.com

Corresponding editor: Yu Lei.

Jordan M. Marshall

marshalj@pfw.edu

1 Department of Biology, Purdue University Fort Wayne, Fort Wayne, IN 46805, USA

2 School of Forest Resources and Environmental Science, Michigan Technological University, Houghton, MI 49931, USA (steeper regression slope), consistent (lower variance), and effective (greater wound closure) growth. Those vigorously growing trees likely had more capacity to repair damage caused by emerald ash borer, leading to healthier trees in our categorization. Linking previous host growth patterns to health may have implications related to identifying individual trees potentially tolerant to attack.

Keywords Agrilus · Ash · Dendrochronology · Emerald ash borer $\cdot$ Fraxinus $\cdot$ Invasive species

\section{Introduction}

Plant suitability for a pest insect is likely to align with the stress or vigor level of an individual host. However, there are two competing hypotheses as to which host type is more suitable: a stressed or vigorous individual host (Price 1991; White 1984). While these hypotheses originated based on specific pest-host interactions (stress hypothesis: psyllids (White 1984); vigor hypothesis: galling and shoot borers (Price 1991)), support exists for both, which may be system and interaction dependent. The plant vigor hypothesis suggests that pest insects are more successful and preferentially feed on vigorously growing plants (Price 1991; Inbar et al. 2001). The plant stress hypothesis suggests the opposite with stressed plants being more suitable (White 1969, 1984). These may be extremes and an intermediate stress hypothesis may be appropriate in other plant-insect interactions, especially where pulses of stress and recovery are more beneficial to insects (Huberty and Denno 2004).

First detected in 2002, emerald ash borer (Agrilus planipennis Fairmaire) was probably introduced to North America via wood packing material imported from Asia (Poland and McCullough 2006). Cross-dating analysis of cores from the 
affected area suggests that emerald ash borer went undetected for nearly 10 years and was introduced to southeastern Michigan, USA, and Ontario, Canada, in the early- to mid1990s (Siegert et al. 2014). Since introduction, emerald ash borer has spread across much of the eastern half of the USA and Canada (Herms and McCullough 2014). All North American ash species (Fraxinus spp.) are susceptible to attack, including relatively healthy individuals (Liu et al. 2003; Cappaert et al. 2005; Anulewicz et al. 2006; Rebek et al. 2008).

The decline of ash and subsequent mortality is caused by the feeding of emerald ash borer larvae on vascular cambium and phloem layers of the tree (Bauer et al. 2004). Even in large, healthy trees, mortality can occur in a few years (Poland and McCullough 2006). Estimates regarding ash loss and potential retention in North American forests are broad, but agree that millions of trees have been lost to emerald ash borer and millions more are still at high risk of infestation (Cappaert et al. 2005; Poland and McCullough 2006; Marshall et al. 2013). Such loss has the potential for large-scale economic impacts, especially in urban forests where ash are removed and replaced (Vannatta et al. 2012). Mortality rates are related to the relative density of emerald ash borer larvae within trees, with high tree loss rates occurring in forest stands that are heavily infested (Marshall et al. 2009). Ash phloem connecting the crown to the roots becomes severed as emerald ash borer larvae feed and progress through developmental instars. Such severing needs to be repaired in order for the tree to survive. Previous growth rates and wound closure abilities may have an influence on the likelihood that an individual tree will succumb to, or survive damage (Shortle et al. 2003).

While the vast majority of ash do succumb to attack by emerald ash borer, there are some individual trees that survive and exhibit some level of resiliency (Marshall et al. 2013). Cipollini et al. (2011) demonstrated that there are clear differences between the phloem chemistries of North American ash species and those found in Manchurian ash. Since Manchurian ash co-evolved with emerald ash borer, there may be factors other than phloem chemistry leading to individual North American ash survival. The objectives of this study were to (1) quantify the growth rates of ash trees along a gradient of tolerance to emerald ash borer attack; (2) identify wound closure within the tolerance gradient; and (3) test the hypothesis that growth rates and wound closure influence presence of emerald ash borer attack signs.

\section{Materials and methods}

\section{Study areas and trees}

Eighty natural forest green ash (Fraxinus pennsylvanica Marshall) trees were selected from sites within the Huron-
Clinton Metroparks, Michigan, USA. Ash trees were randomly selected from previous surveys conducted in the study sites (Marshall et al. 2013; Hietala 2013) along a gradient of apparent host tolerance to emerald ash borer attack in Kensington $\left(83.632^{\circ} \mathrm{W}, 42.572^{\circ} \mathrm{N}\right)$, Lower Huron $\left(83.422^{\circ} \mathrm{W}, 42.183^{\circ} \mathrm{N}\right)$, Oakwoods $\left(83.344^{\circ} \mathrm{W}, 42.114^{\circ} \mathrm{N}\right)$, and Willow $\left(83.363^{\circ} \mathrm{W}, 42.125^{\circ} \mathrm{N}\right)$ Metroparks in Oakland and Wayne Counties, Michigan. The sites were $(24.1 \pm 7.4) \mathrm{km}$ from the de facto location of original introduction for emerald ash borer in North America (Siegert et al. 2014; Fig. 1). Diameter at breast height (DBH, $1.3 \mathrm{~m}$ above soil surface) was measured for each tree. Visual health assessments were made during earlyJuly 2013 following full leaf expansion and included vigor rating (overall tree health categories: $1=$ healthy with no large dead branches, few dead twigs; $2=$ occasional large dead branches, some dead twigs; $3=$ several large dead branches, more bare twigs showing; $4=$ crown half dead; $5=$ crown over half dead), percent crown dieback (percent of fine twigs without leaves), and signs of emerald ash borer infestation (bark splits, exit holes, and woodpecker activity). These assessments were used to categorize trees into apparent tolerance groups based on Hietala (2013), and described briefly here. High tolerance trees had high overall health ratings (1-2 vigor), low percent crown dieback $(<15 \%)$, and no visible signs of emerald ash borer attack. Intermediate tolerance trees had high overall health

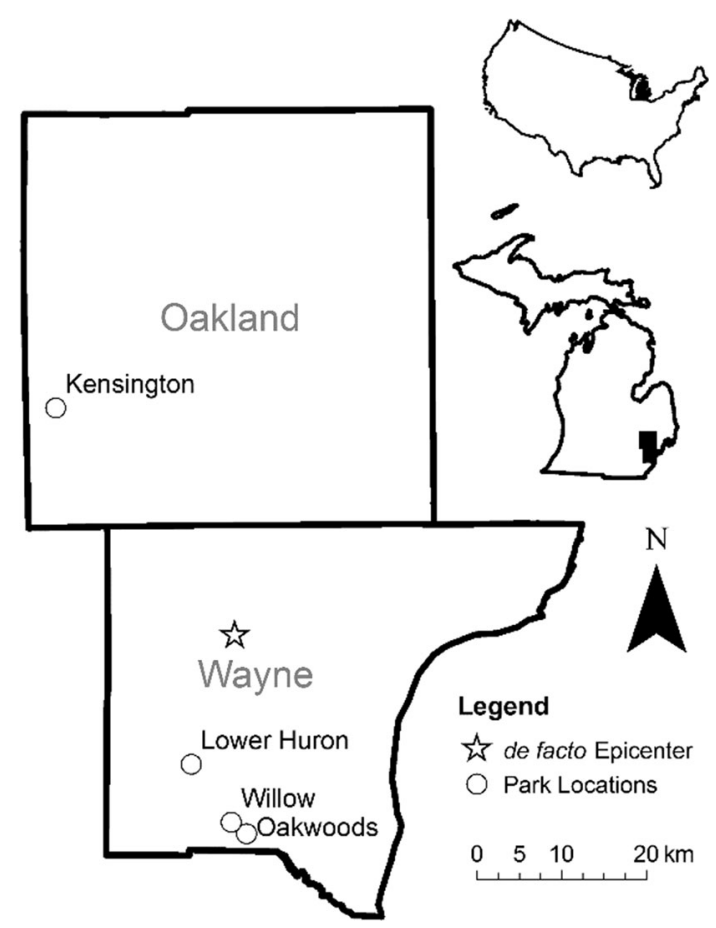

Fig. 1 Study site locations in Oakland and Wayne Counties, Michigan, USA, as well as de facto introduction epicenter for emerald ash borer (Siegert et al. 2014) 
ratings (1-2 vigor), higher percent crown dieback (> 30\%), and at least one visible sign of emerald ash borer attack. Low tolerance trees had low overall health ratings (3-5 vigor), higher percent crown dieback ( $>25 \%)$, and at least one visible sign of emerald ash borer attack. It is important to note that while we did not observe emerald ash borer bark splits, exit holes, or woodpecker activity on high tolerance trees, this did not preclude the possibility that these trees had been attacked by emerald ash borer, which is why we have termed these levels of tolerance and not resistance.

\section{Tree core sampling}

From each selected tree, two cores were collected at breast height and perpendicular to each other during early-July 2013 using a $4.3 \mathrm{~mm}$ diameter increment borer (Haglöf Sweden AB, Långsele, Sweden). Cores were air dried, mounted on wood rails for support, progressively sanded with 220-500 grit sandpaper, and measured to the nearest $0.001 \mathrm{~mm}$ using a Velmex UniSlide with linear encoder and a stereo microscope. Mean ring widths for each tree were converted to ring area (annual basal area growth, $\mathrm{mm}^{2}$ ), which represents overall tree growth better than ring width (Biondi and Qeadan 2008). COFECHA software (version 6.06P) was used to verify cross-dating among series and to identify possible measurement problems. Since all trees were alive when samples were collected with living phloem and had produced early wood during 2013, all series were aligned starting at 2012. While ringporous trees, such as ash (Fraxinus spp.), rarely produce false or missing rings (Phipps 1985), there was still a need to ensure ring measurements were correlated with the created master chronology.

\section{Damage repair}

Thirty trees were randomly selected and damage was applied as 4-6 windows per tree based on DBH (approximately $6 \mathrm{~cm} \times 6 \mathrm{~cm}$ squares) cut in the bark and phloem in August and October 2012 (Hietala 2013). During July 2015, due to time constraints eleven trees were randomly selected $($ high $=4$, intermediate $=3$, low $=4$ ), revisited and wound closure was measured as the width of scar tissue present from the original bark damage on the left and right side (Fig. 2). Mean scar tissue width was calculated per tree.

\section{Data analysis}

Analysis of variance (ANOVA) was used to compare DBH between tolerance groups. Mood's median test was used to test if the count of trees with earliest measurable year were

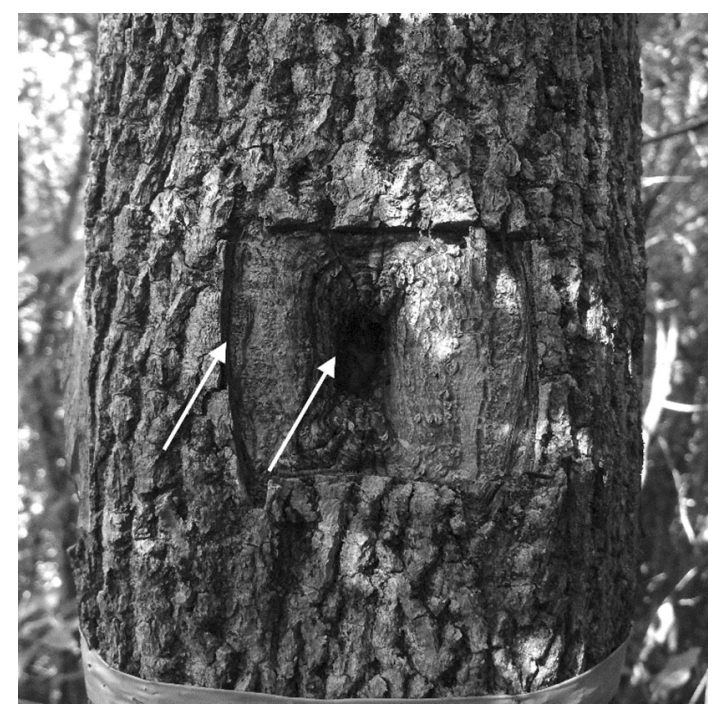

Fig. 2 Example of wound closure in artificially damaged trees. Left arrow indicates left edge of original wound and right arrow indicates scar tissue leading edge

independent of tolerance groups. Ring width indices based on mean ring widths in each tolerance group were calculated using the spline method in R 3.5.1 software (R Core Team 2018) with the dplR library and Pearson's correlation was used to compare ring width indices between tolerance groups. Simple linear regression was used to identify relationships between year and mean annual basal area growth for each tolerance group. Estimated marginal means of tolerance group regression models were calculated using emtrends function in emmeans package in $\mathrm{R}$ and slopes were compared with the pairs function in $\mathrm{R}$ as pairwise $t$ tests with a Holm (1979) $p$ value adjustment. Repeated measures ANOVA was used to compare tolerance group annual basal area growth variance with post hoc pairwise $t$ tests and a Holm (1979) $p$ value adjustment. Annual growth variance was calculated as mean for each of the previous year growth subtracted from the current year growth. Wound closure was compared between tolerance groups using ANOVA with a Tukey's HSD post hoc test. We used logistic regression to test the relationships between wound closure and the presence of signs of emerald ash borer infestation (bark splits, exit holes, and wood pecker activity).

\section{Results}

Thirty-five trees were categorized as high tolerance (Kensington $=14$, Lower Huron $=2, \quad$ Oakwoods $=19$, Willow $=0$ ), 31 as intermediate tolerance (Kensington $=21$, Lower Huron $=2$, Oakwoods $=7$, Willow $=1$ ), and 14 as low tolerance (Kensington $=7$, Lower Huron $=$ 
0 , Oakwoods $=6$, Willow $=1$ ). DBH did not significantly differ between trees within the three tolerance groups and had a pooled mean of $(17.6 \pm 5.7) \mathrm{cm} \quad\left(\mathrm{F}_{2,72}=1.43\right.$, $p=0.245)$. Seven ring series were flagged in the output from COFECHA due to relatively low correlations with the master chronology $(r<0.50$; high tolerance $=4$; intermediate tolerance $=2$; low tolerance $=1$ ). These were also the trees with the shortest ring series (10-14 years). Due to this lack of correlation, these trees were omitted from subsequent analyses.

The median earliest year measured in cores from each of the three tolerance groups was 1995, with high and low tolerance trees having a minimum of 1988 and intermediate tolerance trees of 1985. The number of trees older than the overall median earliest year (1995) was independent of tolerance group $\left(X^{2}=0.64, p=0.727\right)$. Forty-eight percent of high tolerance trees had cores with measurable years before 1995, compared with $52 \%$ of intermediate tolerance trees, and 38\% of low tolerance trees. Both high and intermediate tolerance mean ring width indices had peaks in 1988, with relatively lower values in 1997 (Fig. 3a, b). Low tolerance ring width indices peaked in 1991 and had relatively lower values in 1993 and 1999 (Fig. 3c). Mean ring width indices for high tolerance trees were not correlated with low tolerance trees $(r=-0.36, p=0.080)$. However, mean ring width indices for intermediate tolerance trees were significantly correlated with both high and low tolerance trees $(r=0.63, p<0.001 ; r=-0.42$, $p=0.039$, respectively).

For high and intermediate tolerance groups, simple linear regression analysis relating annual basal area growth $\left(\mathrm{mm}^{2}\right)$ to year resulted in significant equations (Fig. 4a, b). However, low tolerance tree annual basal growth was not significantly related to year (Fig. 4c). Even though the low tolerance tree regression was not significant, it was still included in the slope comparisons for completeness. Regression slopes for all three tolerance groups were significantly different from each other in pairwise comparisons, with high tolerance trees having the steepest regression slope (Fig. 4d). Variance between high, intermediate, and low tolerance group annual basal area growth was significantly different $\left(\mathrm{F}_{2,66}=7.05, p=0.002\right)$. Low tolerance group trees had significantly larger variance when compared post hoc to both intermediate and high tolerance trees ( $p=0.014, p=0.010$, respectively). However, the difference in variance between the intermediate and high tolerance trees was not significantly $(p=0.791)$.

Wound closure, measured as width of scar tissue, was significantly different between tolerance groups $\left(\mathrm{F}_{2,8}=5.07, p=0.038\right)$, with high and low tolerance groups being different from one another (Fig. 5a). Additionally, the probability of exit hole presence was related to wound closure, with lower probability of exit hole presence as wound closure increased $\left(\mathrm{F}_{2,8}=13.86, R^{2}=0.78\right.$, $p=0.003$; Fig. 5b). However, probability of bark split and woodpecker presence were not related to wound closure $\left(\mathrm{F}_{2,8}=2.55, R^{2}=0.39, p=0.140 ; \mathrm{F}_{2,8}=1.07, R^{2}=0.21\right.$, $p=0.387$; respectively).

\section{Discussion}

Since its introduction to North America, emerald ash borer has caused significant mortality in ash species (Poland and McCullough 2006; Kovacs et al. 2010; Marshall et al. 2013). One important characteristic of the pest has been the success of emerald ash borer in a broad range of health categories in ash, with both healthy and stressed trees succumbing to attack (Herms and McCullough 2014). However, a small number of trees appear to have survived exposure to emerald ash borer, even though these trees have signs of attack (Hietala 2013; Marshall et al. 2013). Those trees that have remained provide an important source for data in testing if the plant vigor or plant stress

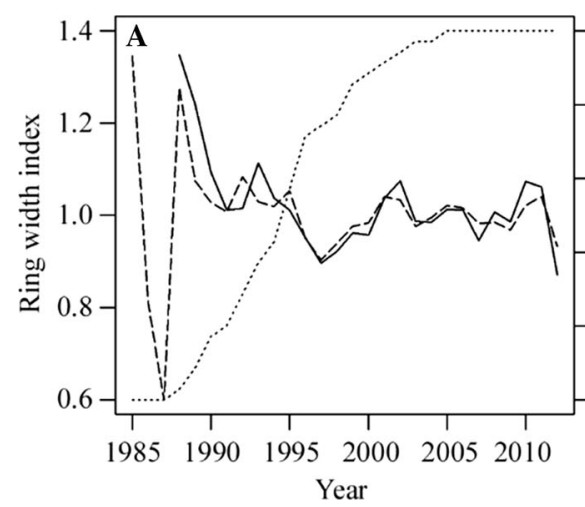

Fig. 3 Ring width indices for tolerance group (solid lines) and master (dashed lines) chronologies, with sampling depth proportion (dotted lines). a High tolerance group; b intermediate tolerance group; c low
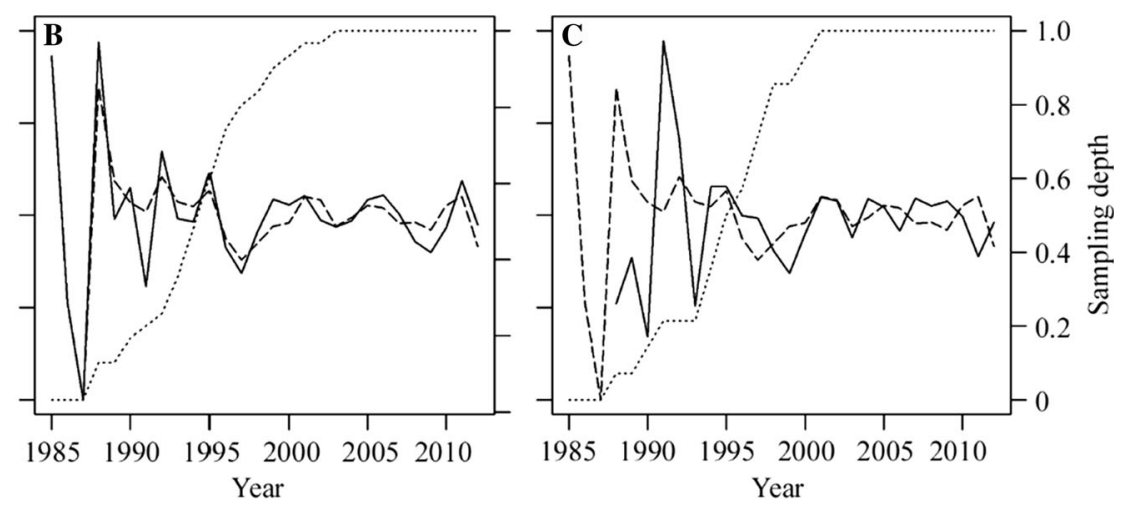

tolerance group. Detrending of original mean ring widths via spline method and master constructed from all trees 

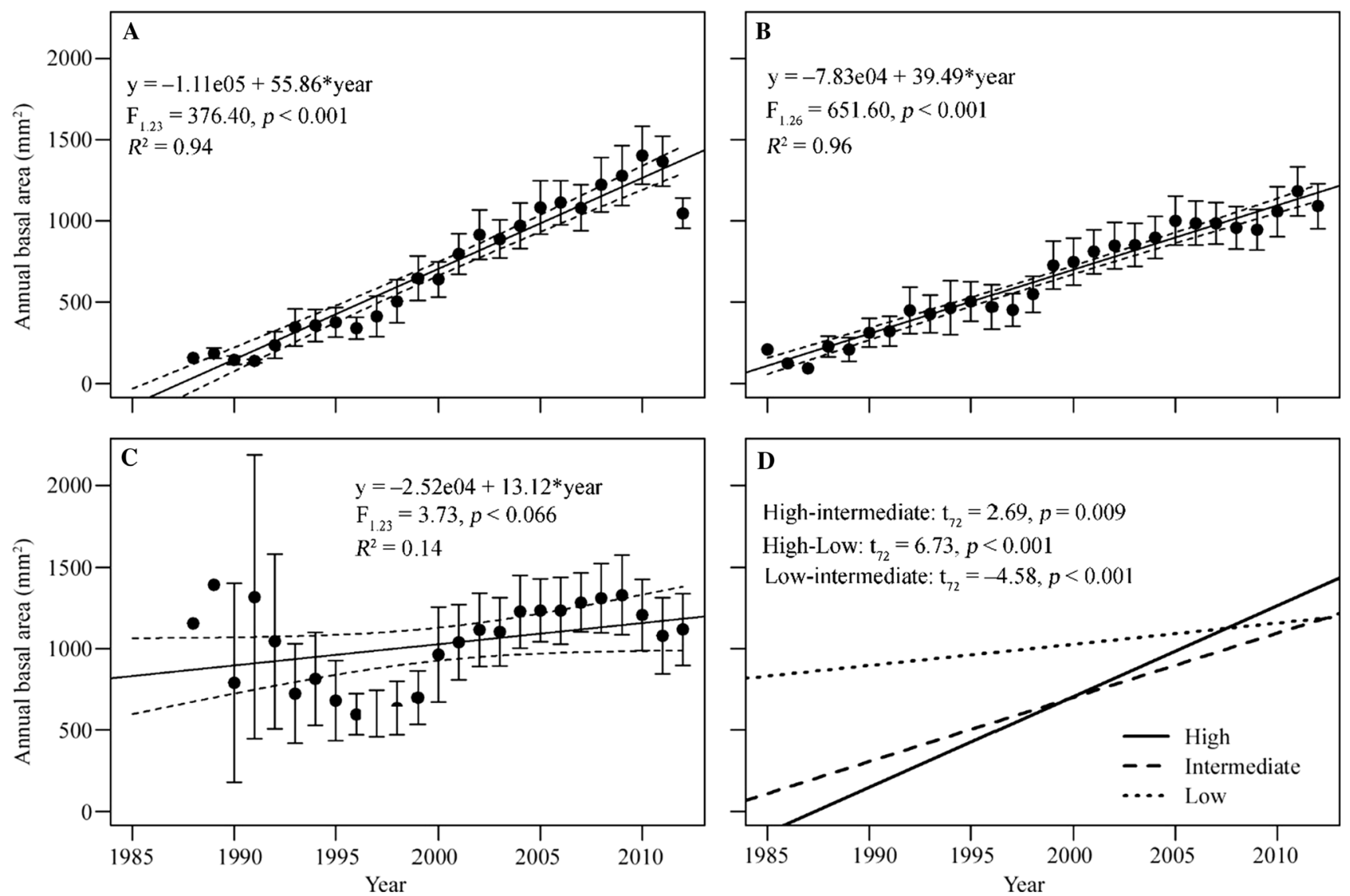

Fig. 4 Simple linear regression between mean annual basal area growth and year, with standard deviation and 95\% confidence intervals (dashed lines). a High tolerance group; b intermediate tolerance group; c low tolerance group; $\mathbf{d}$ regression slope comparison between groups

Fig. 5 Mean closure of artificial wounds. a Between ash tree tolerance to emerald ash borer group comparison; b sigmoidal relationship between probability of emerald ash borer exit hole presence and wound closure in ash trees
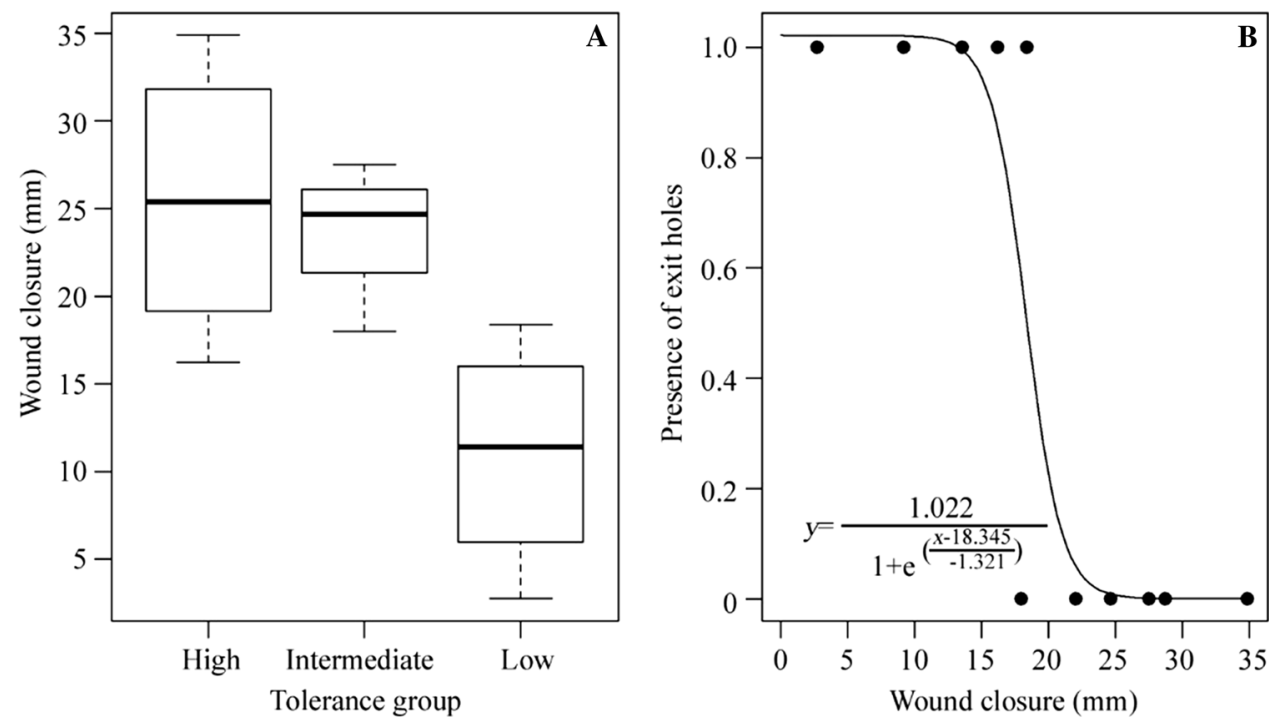

hypothesis aided in explaining ash survival in the presence of emerald ash borer. Our objectives focused on understanding variation in growth rates, wound closure, and attack by emerald ash borer. We applied the plant stress hypothesis in an effort to explain differences in the presence of emerald ash borer attack signs in light of slower, variable growth rates and reduce wound closure rates.

We were able to separate trees using tolerance groups described by Hietala (2013), which were defined by vigor 
rating, percent crown dieback, and signs of emerald ash borer attack. Trees categorized into these tolerance groups were of similar size and we were able to collect cores that were measurable back to similar years in each tolerance group. While trees were not different in DBH, their growth rates and patterns differed, as evidenced by both ring width indices and annual basal area growth analyses. High tolerance trees had a steeper slope (faster growth rate) than both intermediate and low tolerance trees. Additionally, the low tolerance trees had significantly greater variance across years (less consistent growth) than both intermediate and high tolerance trees.

Faster, consistent growth rates leading to attack resistance or resilience aligns with studies for other beetle taxa. Hard (1985) identified patterns in white spruce (Picea glauca [Moench] Voss) resistance and resilience under attack by spruce beetle (Dendroctonus rufipennis [Kirby]), where unattacked trees had the greatest radial growth, killed trees had the least radial growth, and unsuccessfully attacked trees were in between. Similarly, the threshold for a successful attack by Ips typographus L. in Norway spruce (Picea abies [L.] Karst.) increased with increasing vigor (a ratio of basal area incremental growth and sapwood area; Mulock and Christiansen 1986). Radial growth in white oaks (Quercus alba L.) prior to infestation was significantly lower in trees subsequently colonized by twolined chestnut borer (Agrilus bilineatus [Weber]), a congener of emerald ash borer (Dunn et al. 1990). These examples support our interpretation that tree growth rates may provide an indication of resilience against pest attack; those trees with faster, more consistent growth rates have the highest likelihood of survival.

Price (1991) supported the plant vigor hypothesis, arguing that herbivorous pests benefit from vigorous host plants. This was posed as an alternative to the plant stress hypothesis where pests are more successful feeding on stressed plants (e.g. White 1969). Our results align more with the plant stress hypothesis, in which high tolerance trees exhibit higher growth rate and greater wound closure capacity compared to the low tolerance trees. Since the stress and vigor hypotheses provide differing explanations as to how pest insects interact with their host plant, especially those with a limited host range, conservative interpretation and application should be employed to explain an observed interaction. However, they still provide a framework for testing and explaining likely reasons for why a pest herbivore may select individual host plants. Both Price (1991) and Inbar et al. (2001) found support for the plant vigor hypothesis using endophytic insects. However, our endophytic insect (emerald ash borer) seems to align more with the plant stress hypothesis.

By categorical definition, the high tolerance trees had highest vigor (rating 1 or 2) compared to the low tolerance trees (rating 3-5). As wound closure values increased, the likelihood of emerald ash borer exit holes decreased. Vigorously growing trees with the ability to close the artificial phloem wounds likely were able to close the wounds produced by emerald ash borer as they fed in the phloem. Twolined chestnut borer has reduced success in oaks that have the ability to rapidly grow callus tissue and reconnect phloem (Dunn et al. 1990). Wound closure is a fairly precise measure of overall tree vigor; with suitable resource availability, trees can produce callus tissue and reconnect phloem (Neely 1970). By extension, the reduced likelihood of emerald ash borer exit holes as wound closure increased may be related to the ability of those vigorously growing trees to produce callus tissue as larvae feed. For other boring beetles, tree vigor and wound closure aligns with resilience to attack, with those trees closing wounds having reduced infestation rates (e.g. Dunn et al. 1990; Katovich et al. 2000; Fierke and Stephen 2008). Along with our results, those reported by Dunn et al. (1990) and summarized by Katovich et al. (2000) suggest that phloem feeding borers (i.e. Agrilus spp.) may preferentially select stressed hosts, likely due to callus tissue growth limitations.

It is important to keep in mind that all trees included in this study were green ash, which accounted for over $90 \%$ of the surviving ash within these forests (Marshall et al. 2013). While white ash (F. americana L.) did occur in the forest, it was much rarer in numbers. Adult capture rates have not differed between green and white ash in trapping studies (Marshall et al. 2009, 2010), which suggests an indifference in host selection in natural forests.

Because the high tolerance trees have maintained vigorous and consistent growth, they persist within the forest and may limit emerald ash borer emergence. The intermediate tolerance trees, while consistent in growth, were growing slower than the high tolerance trees and may lead to lower overall individual health. Finally, low tolerance trees were both slower and inconsistent in growth, making them the most susceptible to attack by emerald ash borer. There are high costs associated with removal and replacement of trees by urban foresters (Kovacs et al. 2010). By linking previous tree growth patterns to host health, these results have implications in identifying resilient individuals prior to heavy infestation by emerald ash borer (Clark et al. 2015). Mature trees with rapid, consistent growth should be retained within forests to ensure survival of ash within the tree community.

Acknowledgements The authors thank Kelley Boyes, Ryan Boyes, Rachel Harman, Maja Sljivar, and Cecelia Smith for their assistance in field and laboratory data collection. Additionally, the authors thank the Huron-Clinton Metroparks for their continuing cooperation. 
Open Access This article is distributed under the terms of the Creative Commons Attribution 4.0 International License (http://crea tivecommons.org/licenses/by/4.0/), which permits unrestricted use, distribution, and reproduction in any medium, provided you give appropriate credit to the original author(s) and the source, provide a link to the Creative Commons license, and indicate if changes were made.

\section{References}

Anulewicz AC, McCullough DG, Miller DL (2006) Oviposition and development of emerald ash borer (Agrilus planipennis) (Coleoptera: Buprestidae) on hosts and potential hosts in nochoice bioassays. Great Lakes Entomol 39:99-112

Bauer LS, Haack RA, Miller DL, Petrice TR, Liu H (2004) Emerald ash borer life cycle. In: Mastro V, Reardon R (comps) Emerald Ash Borer Research and Technology development meeting. FHTET-2004-02. Forest Health Technology Enterprise Team, Morgantown, WV, P 8

Biondi F, Qeadan F (2008) A theory-driven approach to tree-ring standardization: defining the biological trend from expected basal area increment. Tree-Ring Res 64:81-96

Cappaert D, McCullough DG, Poland TM, Siegert NW (2005) Emerald ash borer in North America: a research and regulatory challenge. Am Entomol 51:152-165

Cipollini D, Wang Q, Whitehill JG, Powell JR, Bonello P, Herms DA (2011) Distinguishing defensive characteristics in the phloem of ash species resistant and susceptible to emerald ash borer. J Chem Ecol 37:450-459

Clark RE, Boyes KN, Morgan LE, Storer AJ, Marshall JM (2015) Development and assessment of ash mortality models in relation to emerald ash borer infestation. Arbor Urban For 41:270-278

Dunn JP, Potter DA, Kimmerer TW (1990) Carbohydrate reserves, radial growth, and mechanisms of resistance of oak trees to phloem-boring insects. Oecologia 83:458-468

Fierke MK, Stephen FM (2008) Callus formation and bark moisture as potential physical defenses of northern red oak, Quercus rubra, against red oak borer, Enaphalodes rufulus (Coleoptera: Cerambycidae). Can Entomol 140:149-157

Hard JS (1985) Spruce beetles attack slowly growing spruce. For Sci 31:839-850

Herms DA, McCullough DG (2014) Emerald ash borer invasion of North America: history, biology, ecology, impacts, and management. Annu Rev Entomol 59:13-30

Hietala KG (2013) Evaluation and monitoring of ash (Fraxinus spp.) tolerant to long-term emerald ash borer (Agrilus planipennis [Coleoptera: Buprestidae]) exposure. M.S. thesis, Michigan Technological Univ, Houghton, MI. 53 p

Holm S (1979) A simple sequentially rejective multiple test procedure. Scand J Stat 6:65-70

Huberty AF, Denno RF (2004) Plant water stress and its consequences for herbivorous insects: a new synthesis. Ecology 85:1383-1398

Inbar M, Doostdar H, Mayer RT (2001) Suitability of stressed and vigorous plants to various insect herbivores. Oikos 94:228-235

Katovich SA, Munson AS, Ball J, McCullough D (2000) Bronze birch borer. Forest insect and disease leaflet 111. USDA Forest
Service, State and Private Forestry, Northeastern Area, Newtown, PA. 7 p

Kovacs KF, Haight RG, McCullough DG, Mercader RJ, Siegert NW, Liebhold AM (2010) Cost of potential emerald ash borer damage in U.S. communities, 2009-2019. Ecol Econ 69:569-578

Liu H, Bauer LS, Gao R, Zhao T, Petrice TR, Haack RA (2003) Exploratory survey for the emerald ash borer, Agrilus planipennis (Coleoptera: Buprestidae), and its natural enemies in China. Great Lakes Entomol 36:191-204

Marshall JM, Smith EL, Mech R, Storer AJ (2013) Estimates of Agrilus planipennis infestation rates and potential survival of ash. Am Midl Nat 169:179-193

Marshall JM, Storer AJ, Fraser I, Beachy JA, Mastro VC (2009) Effectiveness of differing trap types for the detection of emerald ash borer (Coleoptera: Buprestidae). Environ Entomol 38:1226-1234

Marshall JM, Storer AJ, Fraser I, Mastro VC (2010) Efficacy of trap and lure types for detection of Agrilus planipennis (Col., Buprestidae) at low density. J Appl Entomol 134:296-302

Mulock P, Christiansen E (1986) The threshold of successful attack by Ips typographus on Picea abies: a field experiment. For Ecol Man 14:125-132

Neely D (1970) Healing of wounds on trees. J Am Soc Hortic Sci 95:536-540

Phipps RL (1985) Collecting, preparing, crossdating, and measuring tree increment cores. US Geological Survey, water-resources investigations report, 85-4148, Washington, DC, $48 \mathrm{p}$

Poland TM, McCullough DG (2006) Emerald ash borer: invasion of the urban forest and the threat to North America's ash resource. J For 104:118-122

Price PW (1991) The plant vigor hypothesis and herbivore attack. Oikos 62:244-251

R Core Team (2018) R: A language and environment for statistical computing. R Foundation for Statistical Computing, Vienna, Austria http://www.r-project.org/

Rebek EJ, Herms DA, Smitley DR (2008) Interspecific variation in resistance to emerald ash borer (Coleoptera: Buprestidae) among North American and Asian ash (Fraxinus spp.). Environ Entomol 37:242-246

Shortle WC, Smith KT, Dudzik KR (2003) Tree survival and growth following ice storm injury. U.S.D.A. Forest Service, Northeastern Research Station, NE-723, Durham, New Hampshire, 4 p

Siegert NW, McCullough DG, Liebhold AM, Telewski FW (2014) Dendrochronological reconstruction of the epicenter and early spread of emerald ash borer in North America. Divers Distrib 20:847-858

Vannatta AR, Hauer RH, Schuettpelz NM (2012) Economic analysis of emerald ash borer (Coleoptera: Buprestidae) management options. J Econ Entomol 105:196-206

White TCR (1969) An index to measure weather-induced stress of trees associated with outbreaks of psyllids in Australia. Ecology 50:905-909

White TCR (1984) The abundance of invertebrate herbivores in relation to the availability of nitrogen in stressed food plants. Oecologia 63:90-105

Publisher's Note Springer Nature remains neutral with regard to jurisdictional claims in published maps and institutional affiliations. 